ZOOLOGIA 28 (6): 789-802, December, 2011

doi: $10.1590 / S 1984-46702011000600013$

\title{
Morphometric and morphological variation in South American populations of Myotis albescens (Chiroptera: Vespertilionidae)
}

\author{
Ricardo Moratelli' ${ }^{1}$ \& João Alves de Oliveira²
}

\author{
${ }^{1}$ Campus Fiocruz da Mata Atlântica, Fundação Oswaldo Cruz. Estrada Rodrigues Caldas 3400, Pavilhão Olympio da \\ Fonseca Filho, Taquara, Jacarepaguá, 22713-375 Rio de Janeiro, RJ, Brazil. E-mail: rmoratelli@fiocruz.br \\ ${ }^{2}$ Departamento de Vertebrados, Museu Nacional, Universidade Federal do Rio de Janeiro. Quinta da Boa Vista, São \\ Cristóvão, 20940-040 Rio de Janeiro,RJ,Brazil.E-mail: jaoliv@mn.ufrj.br \\ ${ }^{3}$ Corresponding author.
}

\begin{abstract}
Myotis albescens (É. Geoffroy, 1806) occurs from Mexico to Uruguay and Argentina. Despite a large number of specimens in collections, its variability in South America has been underestimated, potentially leading to errors in identification. In order to clarify the taxonomic limits of M. albescens and to evaluate previous hypotheses of geographic variation in size we analyzed the type material and studied the variability in South American samples using multivariate exploratory and confirmatory procedures, as well as frequency analyses of discrete morphological data. The presence of a fringe of hairs along the trailing edge of the uropatagium, the long and silky pelage with frosted appearance on the dorsum, ear 9 to $14 \mathrm{~mm}$ long, broad interorbital and postorbital constrictions, and a globular braincase were identified as the most useful traits to distinguish M. albescens from its South American congeners. In agreement with Bergman's rule, larger specimens were found in the South. Beyond the geographic component, Individual variation is an important factor affecting the variability in the size and shape of the skull and pelage color.
\end{abstract}

KEY WORDS. Myotis; Myotinae; South America; taxonomy.

Myotis Kaup, 1829 (Vespertilionidae: Myotinae) comprises a worldwide group of vespertilionid bats, with more than one hundred species (Simmons 2005). Fifteen South American species are currently recognized (WILSON 2008, Moratelli \& WiLSON 2011a, Moratell et al. 2011a). Among these, Myotis albescens (É. Geoffroy, 1806) has one of the largest distributions in the genus (WILSON 2008), occurring from southern Veracruz, Mexico, southward through Central America to Uruguay and Argentina (Simmons 2005, Wilson 2008, Braun et al. 2009).

Myotis albescens is well represented in collections ( $\mathrm{LAV}_{\mathrm{AL}}$ 1973). A set of traits outlined by previous authors (e.g., LAVAL 1973, Barquez et al. 1999, López-González et al. 2001, LópezGonZÁlez 2005), and summarized in WiLSON (2008) and Braun et al. (2009), is currently used to identify individuals and to characterize the species. Nevertheless, based on the analyses of South American samples of $M$. albescens, we observed both quantitative and qualitative variability in the diagnostic traits, which limit their use in diagnosing the species. In addition, previous analyses of geographic variation in South American populations of $M$. albescens were inconclusive with regards to a trend of larger specimens from north to south (LAVAL 1973, Myers \& Wetzel 1983, López-González et al. 2001).

Herein, as part of an ongoing systematic and biogeographic review of South American species of Myotis, we analyzed the type material and studied the morphological and morphometric variation in available samples of $M$. albescens from South America. These approaches permitted us to redefine the taxonomic limits of the species and to test the hypothesis that specimens of $M$. albescens tend to be larger in Southern locations.

\section{MATERIAL AND METHODS}

To address the variation in qualitative and quantitative characters among South American population samples, 455 specimens (256 females and 199 males, Appendix) were examined. These specimens were identified as M. albescens based on a set of traits present in the neotype (AMNH 205195), as well as other characters highlighted by LAVAL (1973), LóPEZ-GonZÁLEZ et al. (2001) and Moratelli \& Wilson (2011a, b): presence of a fringe of hairs on the trailing edge of the uropatagium; pelage frosted, long and silky, with light brown dorsal hairs, and yellow to whitish ventral hairs; broad interorbital constriction; globular braincase; and moderate overall size (ear length $c a$. 10-14 mm, greatest length of skull ca. 13.2-14.5 mm). These characters occur individually in other South American species of Myotis, but together they are exclusive to M. albescens (Moratelli \& Wilson 2011b). Specimens that exceeded the dimensions provided above were assigned to M. albescens based on cranial morphology and pelage color. 
Fifteen cranial and four external dimensions were measured using a digital caliper accurate to $0.02 \mathrm{~mm}$. The measurements, reported in millimeters $(\mathrm{mm})$, and their abbreviations are defined as follows (lengths were measured from the anteriormost extreme of the first structure to the posteriormost extreme of the second structure mentioned below): greatest length of skull (GLS), from the premaxillae, including the incisors, to the occiput; condylo-canine length (CCL), from the occipital condyles to the upper canines; condylo-incisive length (CIL), from the occipital condyles to the upper incisors; basal length (BL), from the foramen magnum to the upper incisors; zygomatic breadth (ZB), greatest breadth across the outer edges of the zygomatic arches; mastoid breadth (MAB), greatest cranial breadth across the mastoid region; braincase breadth (BCB), greatest breadth of the globular part of the braincase; interorbital breadth (IOB), least breadth across orbital bulges; postorbital breadth (POB), least breadth across frontals posterior to the postorbital bulges; breadth across canines (BAC), greatest breadth across outer edges of the crowns of upper canines; breadth across molars (BAM), greatest breadth across outer edges of the crowns of upper molars; maxillary toothrow length (MTL), from the upper canine crown to the crown of M3; molariform toothrow length (M13), from the crown of M1 to the crown of M3; mandibular length (MAL), from the dentary, without incisors, to the angular process; mandibular toothrow length (MAN), from the lower canine to $\mathrm{m} 3$; forearm length (FA), from the elbow to the distal end of the forearm including carpals; third metacarpal length (3ML), from the distal end of the forearm to the distal end of the third metacarpal; and length of the dorsal (LDH) and ventral hairs ( $\mathrm{LVH})$, from the base to the tip of the hair, measured between scapulas. The weight, reported in grams, and ear length (EL), in millimeters, were obtained from the skin labels. Descriptive statistics were calculated for all dimensions above.

To assess secondary sexual dimorphism of craniodental and external variables we performed a series of analyses of variance (ANOVAs) for locality samples with at least 10 individuals of each gender, as follows: São Gabriel da Cachoeira, Amazonas, Brazil (13 females, 17 males) and Paiçandu, Paraná, Brazil (10 females, 10 males).

Due to the limited number of specimens from some localities, the available specimens were grouped to form pooled samples for the geographic analyses. To define the optimum number of pooled samples and respective sample memberships, the matrix of geographic coordinates was submitted to a $k$ means procedure (HARDY 1994). This procedure iteratively minimizes the least-squared geographic distances between each locality and centroids of all possible locality-groups using the $C_{g}$ criterion of KRZANowski \& LaI (1988). Based on this procedure, a total of 189 specimens recognized as M. albescens were indexed to six geographical samples (Fig. 1), as follows: Group 1 (Uruguayan sample, $\mathrm{n}_{\text {total }}=12$ ): Belén, $6 \mathrm{~km} \mathrm{NW}$, Artigas, Uruguay $(\mathrm{n}=12)$; Group 2 (Paraná sample, $\mathrm{n}_{\text {total }}=36$ ): Maringá,
Paraná, Brazil $(\mathrm{n}=1)$, Paiçandu, Paraná, Brazil $(\mathrm{n}=21)$, Porto Rico, Paraná, Brazil ( $\mathrm{n}=1)$; Curuguaty, Canindeyú, Paraguay $(\mathrm{n}=10)$, Tacuaral, Cordillera, Paraguay $(\mathrm{n}=2)$, and Yaguarón, Paraguari, Paraguay $(\mathrm{n}=1)$; Group 3 (Bolivian sample, $\mathrm{n}_{\text {total }}=$ 13): Andres Ibanez, Santa Cruz, Bolivia $(n=1)$, Mamore, Beni, Bolivia ( $(=8)$, Marban, Beni, Bolivia $(n=1)$, Vaca Diez, Beni, Bolivia ( $(=1)$, and Yacuma, Beni, Bolivia $(n=2)$; Group 4 (Peruvian sample, $\mathrm{n}_{\text {total }}=16$ ): Paktiza, Madre De Dios, Peru ( $\mathrm{n}=$ 1), Oxapampa, Pasco, Peru ( $\mathrm{n}=3)$, San Juan, Pasco, Peru ( $\mathrm{n}=$ 10), unknown locality, Loreto, Peru $(\mathrm{n}=1)$, and unknown locality, Pasco, Peru ( $\mathrm{n}=1)$; Group 5 (Amazonian sample, $\mathrm{n}_{\text {total }}=$ 71): Airão, Amazonas, Brazil $(\mathrm{n}=4)$, Borba, Amazonas, Brazil $(\mathrm{n}=5)$, Manicoré, Amazonas, Brazil $(\mathrm{n}=11)$, Humaitá, Amazonas, Brazil $(n=1)$, Altamira, Pará, Brazil $(n=5)$, Aveiro, Pará, Brazil $(n=4)$, Baião, Pará, Brazil $(n=16)$, Belém, Pará, Brazil $(n=4)$, Faro, Pará, Brazil $(n=11)$, Porto de Moz, Pará, Brazil $(\mathrm{n}=1)$, Santarém, Pará, Brazil $(\mathrm{n}=2)$, and Tapajós River, Pará, Brazil $(\mathrm{n}=7)$; Group 6 (Venezuelan sample, $\left.\mathrm{n}_{\text {total }}=41\right)$ : Capibara, Amazonas, Venezuela $(n=2)$, Cerro Neblina Base Camp, Amazonas, Venezuela ( $\mathrm{n}=1)$, San Juan, Amazonas, Venezuela ( $\mathrm{n}=4)$, Pto. Paez, $38 \mathrm{~km} \mathrm{NW}$, Apure, Venezuela $(\mathrm{n}=1)$, Rio Supamo, Bolivar, Venezuela $(\mathrm{n}=1)$, Rio Chico, $7 \mathrm{~km} \mathrm{E}$, Miranda, Venezuela $(\mathrm{n}=1)$, Valera, $23 \mathrm{~km}$ NW Trujillo, Venezuela $(\mathrm{n}=1)$, and São Gabriel da Cachoeira, Amazonas, Brazil $(\mathrm{n}=30)$.

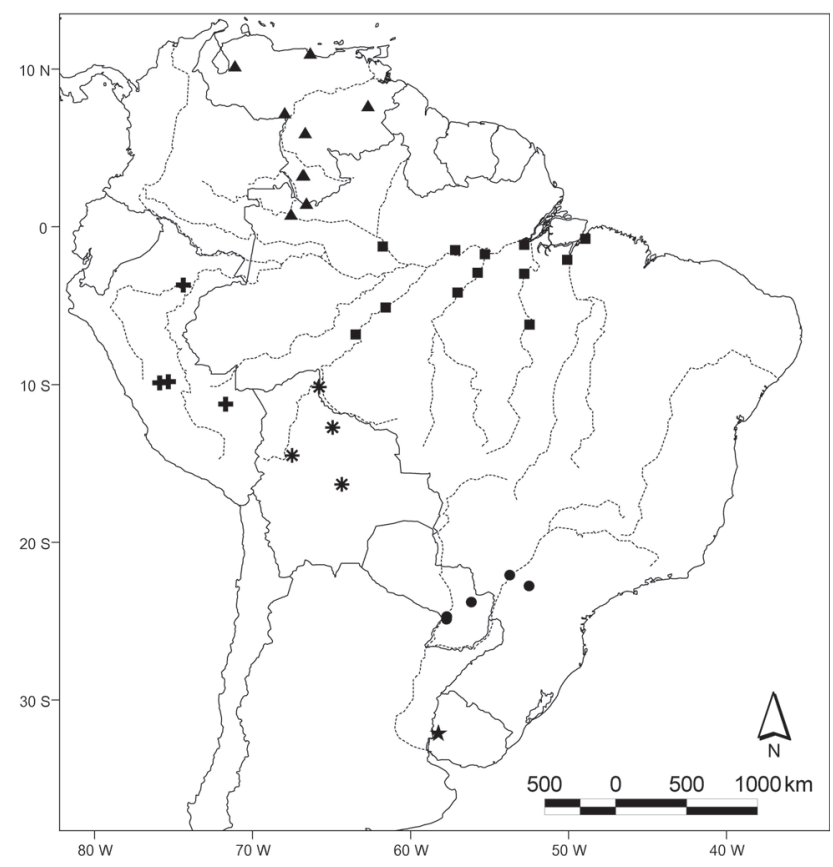

Figure 1. Geographic mapping of samples analyzed in the present study: ( $\star$ ) Uruguay, (@) Paraná, (*) Bolivia, (+) Peru, (ם) Amazon, and $(\boldsymbol{\Delta})$ Venezuela. 
As multivariate procedures require complete datasets, missing values $(2.03 \%$ of total dataset) were estimated from the existing raw data using the Expectation-maximization (EM) algorithm (Little \& Rubin 1987, Strauss et al. 2003). All measurements and estimated values were then log-transformed and the covariance matrices were computed considering all variables. Geographic variation in morphometric characters was accessed by Principal Components Analysis (PCA) to summarize general trends of size and shape variation within the total dataset treated as a unique sample, and Canonical Variate Analysis was used to assess craniometric characters that best discriminate the geographic samples (Nefr \& Marcus 1980, Manly 1994, Strauss 2010).

All statistical procedures, including the $k$-means procedure to define the optimum number of pooled samples and respective sample memberships, the estimation of missing data using the E-M algorithm, as well as the univariate and multivariate analyses were performed in Matlab for Windows, version 4.2c (Mathworks 1994), using functions written by R.E. Strauss available at http://www.faculty.biol.ttu.edu/strauss/ Matlab/Matlab.htm (as accessed in November 07, 2010).

A set of qualitative characters selected by previous authors (e.g., Thomas 1901, 1902, Miller \& Allen 1928, Handley 1960, LaVAL 1973, BAUd \& Menu 1993, López-GonZÁlez et al. 2001, López-González 2005, Wilson 2008, Moratelli \& Wilson 2011a, b, Moratelli et al. 2011a, b) was used to distinguish and characterize $M$. albescens: plagiopatagium attachment (attached at ankles; at toes by a narrow band of membrane; or at toes by a broad band of membrane); occurrence of a fringe of hairs along the trailing edge of the uropatagium (absent or present); position of P3 (aligned with other premolars or displaced to the lingual side, and visible or not visible when observed in labial view); occurrence and height of sagittal and occipital crests (absent or present, and height: very low, low, medium and high); shape of braincase roof (parietal inclined forward or straight); shape of occipital region (occipital flattened when observed in lateral view, not projected much beyond the limit of occipital condyles, or occipital rounded, projected beyond the limit of occipital condyles). In addition to these traits, pelage color was also described and compared to characterize variation in M. albescens. Capitalized color nomenclature standards follow RidgWaY (1912).

\section{RESULTS}

\section{Non-geographic variation}

Quantitative characters: There is considerable variability in the overall size of adult individuals from the same locality. For example, in one sample from the Tocantins River, Pará, Brazil ( $\mathrm{n}=12$ ), the forearm ranges from 32.2 to $36.7 \mathrm{~mm}$ in length, and the total length of skull ranges from 12.88 to 14.08 $\mathrm{mm}$. In another sample from Paiçandu, Paraná, Brazil $(\mathrm{n}=31)$, the length of the forearm ranges from 34.8 to $39.5 \mathrm{~mm}$, and the total length of skull ranges from 13.44 to $14.74 \mathrm{~mm}$. Other measurements contrasting within-group variability are in Tab. I. The analyses of variance did not reveal any significant sexually dimorphic character in the sample from São Gabriel da Cachoeira, Amazonas, and only three out of 11 craniodental characters in the sample from Paiçandu, Paraná, were sexually dimorphic (Tab. II). These results indicate that secondary sexual dimorphism in cranial characters does not have a relevant role in the within-group variation sampled from distinct parts of the geographic range of M. albescens. Based on this result, males and females were pooled in geographic samples.

Qualitative characters: The skull profile varies considerably (Figs 2-5 and Tab, III), even among specimens from the same locality. The rostrum and the braincase are the most variable skull regions. The rostral slope, from the posteriormost region of frontal bone to the anteriormost region of maxillary bone, varies from slight (Fig. 4) to well-marked (Fig. 2). The braincase varies from globular to laterally flattened, with the braincase roof inclined forward or straight (Tab. III). Other characters vary within groups in the same way as among groups (Tab. III). Regarding pelage color, most specimens have bicolored dorsal and ventral pelages, with Cinnamon-brown bases and Antiquebrown tips dorsally and Mummy-brown bases and almost white tips ventrally. However, some individuals are slightly lighter or darker, but differences in skin color seem to be due to individual variation rather than geographically structured.

\section{Geographic variation}

The first two principal components account for $64 \%$ of the total craniometric variation. The first principal component (PC1, 46\%) corresponds to a size vector based on the positive and relatively high magnitudes of all character loadings (Figs 6-8, Tab. IV). PC2 (18\%) presented loadings of opposite signs for correlations with characters, with those related with length of skull (MAN) and rostrum (MTL and M13) contrasting with width of rostrum (POB).

A wide superimposition of scores is revealed for most geographic samples, but PC1 centroids of the Uruguayan sample (group 1) are the largest, followed by the samples from Paraná (group 2), Peru (group 4), Bolivia (group 3), Venezuela (group 6) and Amazon (group 5) (Fig. 6). The 95\% confidence interval of scores of the Uruguayan sample is almost non-overlapping with scores from northernmost samples (groups 5 and 6). PC2 is not informative to the distinction of samples. The sample from Bolivia (group 2) is very variable and encompasses centroids of most samples, except Uruguay.

Similarly to the PC1 x PC2 plot of scores, the first two discriminant functions (CV1 and CV2), which accounted for $90 \%$ of the total discriminatory variation, partially separated two sets of samples, albeit with a wide superimposition mainly due to the sample from Bolivia. Four characters representing length of skull (CIL), length of rostrum (MTL and M13) and width of rostrum (POB) were most associated with CV1 (Figs 7 and 9, Tab. IV). A vector plot of the character loadings on CV1 
Table I. Descriptive statistics, with measurements given in millimeters, for geographic samples (groups 1-6) of Myotis albescens, with males and females pooled.

\begin{tabular}{|c|c|c|c|}
\hline \multirow{2}{*}{ Characters } & Amazon & Venezuela & Peru \\
\hline & Mean (Range) N & Mean (Range) $\mathrm{N}$ & Mean (Range) N \\
\hline FA & $34.6(32.2-36.7) 80$ & - & $35.8(34.4-37.2) 9$ \\
\hline $3 \mathrm{ML}$ & $32.3(30.3-34.5) 81$ & - & $32.9(31.5-34.7) 17$ \\
\hline GLS & 13.89 (13.48-14.54) 66 & $14.13(13.85-14.62) 11$ & 14.17 (13.75-14.59) 23 \\
\hline $\mathrm{CCL}$ & $12.02(11.62-12.59) 67$ & 12.19 (11.91-12.82) 11 & 12.27 (11.70-13.51) 23 \\
\hline CIL & $12.86(12.41-13.35) 66$ & 13.09 (12.79-13.73) 11 & $13.11(12.51-13.51) 23$ \\
\hline$B L$ & $11.48(10.92-13.01) 64$ & 11.66 (11.43-12.24) 11 & 11.70 (11.32-12.09) 22 \\
\hline ZB & $8.33(7.94-8.85) 31$ & $8.52(8.42-8.58) 5$ & $8.36(7.39-8.60) 10$ \\
\hline MAB & $7.12(6.76-7.60) 65$ & $7.28(6.90-7.53) 10$ & $7.22(6.98-7.49) 18$ \\
\hline $\mathrm{BCB}$ & $6.73(6.40-7.01) 66$ & $6.77(6.52-7.01) 11$ & $6.78(6.46-7.01) 22$ \\
\hline $\mathrm{IOB}$ & $4.46(4.16-4.81) 67$ & $4.54(4.36-4.70) 11$ & 4.56 (3.98-4.84) 23 \\
\hline POB & $3.80(3.50-4.08) 67$ & $3.72(3.60-3.88) 11$ & $3.82(3.59-3.96) 23$ \\
\hline BAC & $3.56(3.25-3.78) 65$ & $3.61(3.49-3.83) 11$ & $3.67(3.44-5.41) 20$ \\
\hline BAM & $5.29(4.89-5.64) 67$ & $5.47(5.21-4.77) 11$ & $5.43(5.28-5.66) 22$ \\
\hline MTL & $4.91(4.67-5.24) 67$ & $5.00(4.86-5.12) 11$ & $5.05(4.80-5.24) 23$ \\
\hline M13 & $2.74(2.61-2.90) 67$ & $2.87(2.78-2.92) 10$ & $2.88(2.75-3.03) 23$ \\
\hline MAL & $9.58(9.28-10.18) 18$ & $9.82(9.71-10.12) 6$ & $9.89(9.61-10.18) 9$ \\
\hline \multirow{2}{*}{ Characters } & Bolivia & Paraná, Brazil & Uruguay \\
\hline & Mean (Range) N & Mean (Range) $\mathrm{N}$ & Mean (Range) N \\
\hline FA & $35.1(33.1-38.7) 17$ & $35.7(32.6-39.5) 48$ & $35.2(34.2-35.9) 11$ \\
\hline $3 \mathrm{ML}$ & $32.9(30.2-35.8) 17$ & $33.2(30.1-35.8) 48$ & $33.0(31.4-34.1) 11$ \\
\hline GLS & $14.00(13.41-14.64) 13$ & 14.33 (13.71-15.07) 33 & $14.71(14.28-14.99) 12$ \\
\hline $\mathrm{CCL}$ & $12.12(11.77-12.93) 13$ & $12.36(11.88-12.93) 35$ & $12.77(12.41-13.28) 12$ \\
\hline CIL & $12.98(12.51-13.84) 13$ & 13.25 (12.68-13.81) 33 & 13.45 (11.98-13.85) 12 \\
\hline$B L$ & 11.53 (11.01-12.49) 13 & 11.65 (11.08-12.31) 35 & $12.02(11.66-12.28) 11$ \\
\hline ZB & $8.59(8.28-8.88) 11$ & $8.61(8.19-8.95) 28$ & 8.69 (7.48-9.09) 9 \\
\hline MAB & $7.27(7.15-7.47) 13$ & $7.34(6.99-7.65) 36$ & 7.48 (6.98-7.67) 11 \\
\hline $\mathrm{BCB}$ & $6.88(6.70-7.09) 13$ & $7.00(6.66-7.29) 36$ & $7.03(6.90-7.25) 11$ \\
\hline $\mathrm{IOB}$ & $4.62(4.38-4.87) 13$ & $4.67(4.21-5.03) 36$ & $4.73(4.07-5.01) 12$ \\
\hline POB & $4.01(3.75-4.47) 13$ & $4.04(3.85-4.25) 36$ & $4.05(3.79-4.21) 12$ \\
\hline BAC & $3.55(3.38-3.72) 13$ & 3.68 (3.39-3.84) 36 & $3.88(3.55-5.54) 12$ \\
\hline BAM & $5.31(5.01-5.59) 13$ & $5.36(4.98-5.69) 36$ & $5.50(4.99-5.62) 12$ \\
\hline MTL & $4.87(4.66-5.42) 13$ & $4.99(4.74-5.30) 36$ & $5.11(5.01-5.25) 11$ \\
\hline M13 & $2.76(2.65-3.19) 13$ & $2.83(2.65-3.01) 36$ & $2.97(2.82-3.03) 11$ \\
\hline MAL & $9.61(9.12-10.44) 12$ & $9.83(9.46-10.27) 28$ & 10.06 (9.90-10.31) 5 \\
\hline
\end{tabular}

See text for a description of measurement methods and localities included in each sample.

(x-axis) revealed that the Uruguayan sample (group 1) is distinguished from the Amazonian (group 5), Peruvian (group 4) and Venezuelan (group 6) samples mainly by greater values in
GLS and M13, showing more elongated skulls, whereas Paraná (group 2) and Bolivian (group 3) samples showed intermediate scores. Based on the discontinuities revealed, Uruguayan speci- 


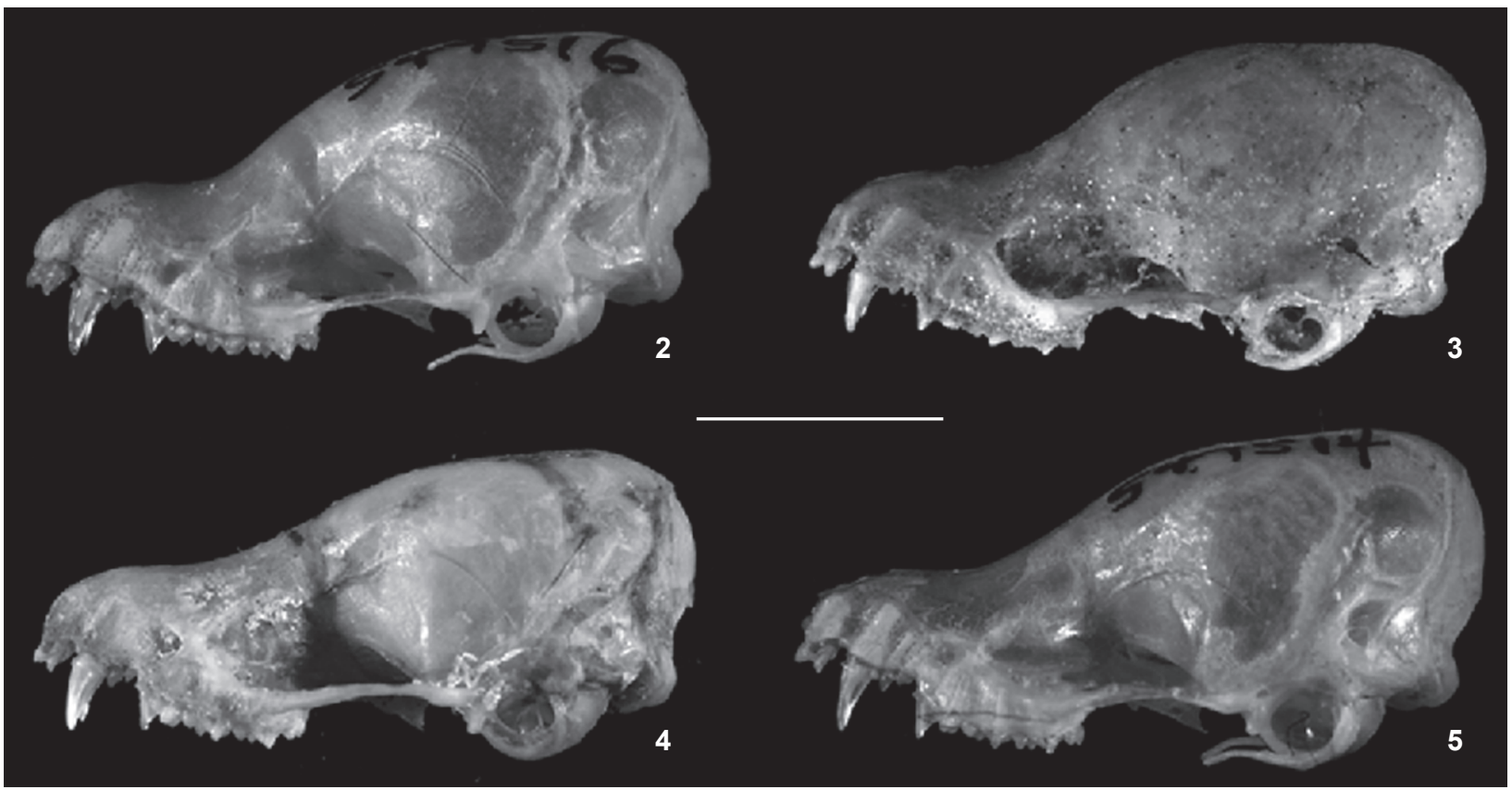

Figures 2-5. Lateral views of the skulls of Myotis albescens emphasizing differences in skull shape: (2) USNM 549516; (3) ALP 5165; (4) AMNH 77398; (5) USNM 549514. Scale bar: $5.0 \mathrm{~mm}$.

Table II. F and $p$ values (ANOVA) for secondary sexual dimorphism in craniometric and external measurements of two samples (São Gabriel da Cachoeira, Amazonas, Brazil, and Paiçandu, Paraná, Brazil) of Myotis albescens. Numbers in bold indicate statistically significant dimorphism $(\mathrm{p}<0.05)$.

\begin{tabular}{|c|c|c|c|c|}
\hline \multirow{2}{*}{ Characters } & \multicolumn{2}{|c|}{$\begin{array}{l}\text { São Gabriel da Cachoeira } \\
\text { (13 females, } 17 \text { males) }\end{array}$} & \multicolumn{2}{|c|}{$\begin{array}{c}\text { Paiçandu ( } 10 \\
\text { females, } 10 \text { males) }\end{array}$} \\
\hline & $\mathrm{F}$ & $\mathrm{p}$ & $\mathrm{F}$ & $\mathrm{p}$ \\
\hline FA & 0.288 & 0.596 & 1.822 & 0.193 \\
\hline GLS & 0.086 & 0.771 & 0.196 & 0.664 \\
\hline $\mathrm{CCL}$ & 0.003 & 0.958 & 0.387 & 0.542 \\
\hline CIL & 0.001 & 0.976 & 0.710 & 0.794 \\
\hline$B L$ & 0.138 & 0.714 & 0.080 & 0.928 \\
\hline ZB & - & - & 1.584 & 0.229 \\
\hline MAB & 0.101 & 0.753 & 0.234 & 0.634 \\
\hline $\mathrm{BCB}$ & 0.624 & 0.436 & 5.460 & 0.031 \\
\hline IOB & 0.000 & 0.983 & 5.777 & 0.027 \\
\hline POB & 0.644 & 0.429 & 1.001 & 0.330 \\
\hline BAC & 0.123 & 0.729 & 5.221 & 0.035 \\
\hline BAM & 0.310 & 0.863 & 0.142 & 0.711 \\
\hline MTL & 0.290 & 0.595 & 0.651 & 0.430 \\
\hline M13 & 2.865 & 0.102 & 0.016 & 0.901 \\
\hline MAL & - & - & 0.056 & 0.817 \\
\hline MAN & 0.011 & 0.919 & 0.578 & 0.457 \\
\hline
\end{tabular}

mens have more elongated skulls in comparison with Amazonian, Peruvian and Venezuelan specimens.

An analysis of the descriptive statistics of craniodental measurements (Tab. I) shows that southernmost samples are, on average, larger than northernmost samples, with specimens from Uruguay (group 1) and Paraná (group 2) being the largest ones, followed by specimens from Bolivia, intermediate in size, and specimens from Peru, Amazon and Venezuela being the smallest. The two external measurements (FA and 3ML) do not distinguish northern and southern samples.

It is interesting to note that the geographically intermediate sample from Bolivia also showed intermediate scores in CV1 with respect to the samples from Southern Brazil and Uruguay and those from the Brazilian Amazon, Peru and Venezuela. This result, together with the size trend revealed by PC1, is indicative that the craniodental variation in $M$. albescens is structured in a trend of increasing size from northern to southern latitudes, without a detectable break at the scale of the analysis allowed by our samples.

\section{TAXONOMY}

\section{Myotis albescens (É. Geoffroy, 1806) Figs 10-16}

Diagnosis: Based on currently available samples, $M$. albescens can be diagnosed as follows: a small to medium species (FA 32.3-39.5 mm, EL 9-14 mm, weight 4-10 g) compared 
Table III. Occurrence and distribution of selected qualitative characters for geographic samples (groups 1-6) of Myotis albescens.

\begin{tabular}{|c|c|c|c|c|c|c|}
\hline \multirow{2}{*}{ Characters } & Uruguay & Paraná & Bolívia & Peru & Amazon & Venezuela \\
\hline & N (\%) & N (\%) & N (\%) & $\mathrm{N}(\%)$ & N (\%) & N (\%) \\
\hline P3 (position regarding other premolars) & Ntotal $=10$ & Ntotal $=21$ & Ntotal $=13$ & Ntotal $=19$ & Ntotal $=105$ & Ntotal $=11$ \\
\hline Displaced and not visible in lateral view & 0 & 0 & 0 & 0 & 0 & 0 \\
\hline Displaced and visible in lateral view & 0 & 0 & 0 & 0 & 0 & 0 \\
\hline Aligned and not visible in lateral view & $1(10.0 \%)$ & $2(9.5 \%)$ & 0 & 0 & 0 & $1(9.1 \%)$ \\
\hline Aligned and visible in lateral view & $9(90.0 \%)$ & $19(90.5 \%)$ & $13(100 \%)$ & $19(100 \%)$ & $105(100 \%)$ & $10(90.9 \%)$ \\
\hline Sagittal crest (occurrence) & Ntotal $=12$ & Ntotal $=23$ & Ntotal $=13$ & Ntotal $=19$ & Ntotal $=104$ & Ntotal $=11$ \\
\hline Absent & $12(100 \%)$ & $22(95.7 \%)$ & $12(92.3 \%)$ & $18(94.7 \%)$ & $88(84.6 \%)$ & $11(100 \%)$ \\
\hline Present & 0 & $1(4.3 \%)$ & $1(7.7 \%)$ & $1(5.3 \%)$ & $16(15.4 \%)$ & 0 \\
\hline Sagittal crest (height) & Ntotal $=0$ & Ntotal = 1 & Ntotal $=1$ & Ntotal $=1$ & Ntotal $=16$ & Ntotal $=0$ \\
\hline Very low & - & 0 & $1(100 \%)$ & $1(100 \%)$ & $15(93.8 \%)$ & - \\
\hline Low & - & $1(100 \%)$ & 0 & 0 & $1(6.2 \%)$ & - \\
\hline Medium & - & 0 & 0 & 0 & 0 & - \\
\hline High & - & 0 & 0 & 0 & 0 & - \\
\hline Occipital crests (occurrence) & Ntotal $=12$ & Ntotal $=14$ & Ntotal $=13$ & Ntotal $=19$ & Ntotal $=96$ & Ntotal $=11$ \\
\hline Absent & $8(66.7 \%)$ & $3(21.4 \%)$ & $6(46.2 \%)$ & $7(36.8 \%)$ & $9(9.4 \%)$ & $1(9.1 \%)$ \\
\hline Present & $4(33.3 \%)$ & $11(78.6 \%)$ & $7(53.8 \%)$ & $12(63.2 \%)$ & $87(90.6 \%)$ & $10(90.9 \%)$ \\
\hline Occipital crests (height) & Ntotal $=4$ & Ntotal $=11$ & Ntotal $=7$ & Ntotal $=12$ & Ntotal $=86$ & Ntotal $=10$ \\
\hline Very low & $4(100 \%)$ & $7(63.6 \%)$ & $3(42.9 \%)$ & $11(91.7 \%)$ & $31(36.0 \%)$ & $4(40.0 \%)$ \\
\hline Low & 0 & $4(36.4 \%)$ & $4(57.1 \%)$ & $1(8.3 \%)$ & $50(58.1 \%)$ & $4(40.0 \%)$ \\
\hline Medium & 0 & 0 & 0 & 0 & $5(5.81 \%)$ & $1(10.0 \%)$ \\
\hline High & 0 & 0 & 0 & 0 & 0 & $1(10.0 \%)$ \\
\hline Braincase roof (shape) & Ntotal $=12$ & Ntotal $=14$ & Ntotal $=13$ & Ntotal $=17$ & Ntotal $=94$ & Ntotal $=11$ \\
\hline Parietal straight & 0 & $3(21.4 \%)$ & $1(7.7 \%)$ & $3(17.6 \%)$ & $10(10.6 \%)$ & 0 \\
\hline Parietal inclined forward & $12(100 \%)$ & $11(78.6 \%)$ & $12(92.3 \%)$ & $14(82.4 \%)$ & $84(89.4 \%)$ & $11(100 \%)$ \\
\hline Occipital region (shape) & Ntotal $=12$ & Ntotal $=14$ & Ntotal $=13$ & Ntotal $=19$ & Ntotal $=95$ & Ntotal $=11$ \\
\hline Occipital rounded & $12(100 \%)$ & $14(100 \%)$ & $13(100 \%)$ & $18(94.7 \%)$ & 95 (100\%) & $7(63.6 \%)$ \\
\hline Occipital flattened & 0 & 0 & 0 & $1(5.3 \%)$ & 0 & $4(36.4 \%)$ \\
\hline Fringe (occurrence in the uropatagium) & Ntotal $=11$ & Ntotal $=36$ & Ntotal $=13$ & Ntotal $=11$ & Ntotal = 131 & Ntotal $=46$ \\
\hline Absent & 0 & 0 & 0 & 0 & 0 & 0 \\
\hline Present & $11(100 \%)$ & $36(100 \%)$ & $13(100 \%)$ & $11(100 \%)$ & $131(100 \%)$ & $46(100 \%)$ \\
\hline Plagiopatagium (insertion) & Ntotal $=11$ & Ntotal $=36$ & Ntotal $=13$ & Ntotal $=11$ & Ntotal = 127 & Ntotal $=19$ \\
\hline At ankles & 0 & 0 & 0 & 0 & 0 & 0 \\
\hline At toes by a narrow band of membrane & 0 & 0 & 0 & 0 & 0 & 0 \\
\hline At toes by a large band of membrane & $11(100 \%)$ & $36(100 \%)$ & $13(100 \%)$ & $11(100 \%)$ & $127(100 \%)$ & 19 (100\%) \\
\hline
\end{tabular}

with other South American Myotis; long and silky pelage (dorsal fur 4-9 mm; ventral fur 3-8 $\mathrm{mm}$ ); dorsal fur bicolored, generally with Antique-brown tips (1/3 of the total length), giving a golden appearance to dorsal pelage; ventral fur strongly bi- colored, generally with white tips (1/3), giving a frosted appearance to ventral pelage; wing and interfemoral membrane colors ranging from Cinnamon-brown to Mummy-brown; plagiopatagium attached to feet by a broad band of membrane 

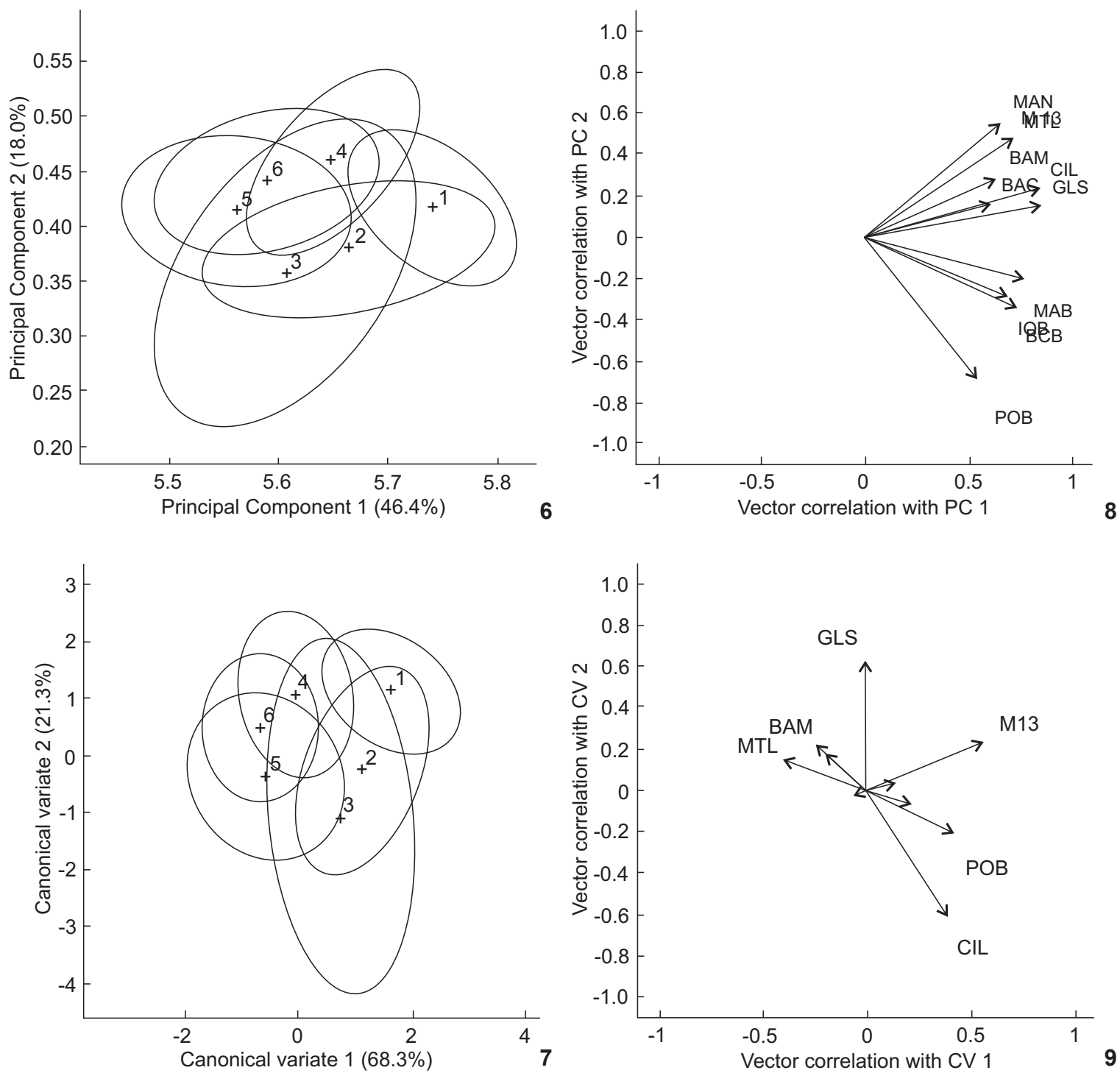

Figures 6-9. (6-7) Scatter plot showing 95\% confidence interval ellipses data of PCA (6) and CVA (7) for samples (+ = samples centroids) indexed by locality: 1) Uruguay, 2) Paraná, 3) Bolivia, 4) Peru, 5) Amazon and 6) Venezuela. (8-9) Vector plot of the loadings (>0.29) on the first two principal component (8) and canonical variate axes (9).

(100\%); fringe of hairs along the trailing edge of uropatagium present (100\%); skull small to moderate in size (GLS 13.5-15.1 $\mathrm{mm}$, MAB 6.7-7.7 $\mathrm{mm}$ ); interorbital and postorbital constrictions generally broad; braincase generally globular; P3 in toothrow and visible in labial view (96\%); sagittal crest absent $(90 \%)$ or present $(10 \%)$, ranging from very low $(89 \%)$ and low (11\%); occipital crests present (79\%) or absent (21\%), ranging from very low (46\%), low (48\%), medium (5\%) and high (1\%); parietal inclined forward (89\%) or straight (11\%); and occipital region rounded $(97 \%)$ or flattened $(3 \%)$. Of the characters listed above, five are useful for field identification: ear length
(9-14 mm); long and silk pelage; tips of dorsal pelage with frosted appearance; fringe of hairs along the trailing edge of uropatagium present; and plagiopatagium attached to feet by a broad band of membrane.

Type specimen: The neotype of Myotis albescens (É. Geoffroy, 1806) is an adult female (AMNH 205195) with skin (Figs 10-11), skull (Figs 12-16) and skeleton, collected by M.D. Tuttle on January 2, 1963 in Yaguarón, Paraguarí, Paraguay, at an elevation of $200 \mathrm{~m}$ (LAVAL 1973). The skin and the skull, including mandible, are complete, with the exception of the left zygomatic arch, which is broken. 


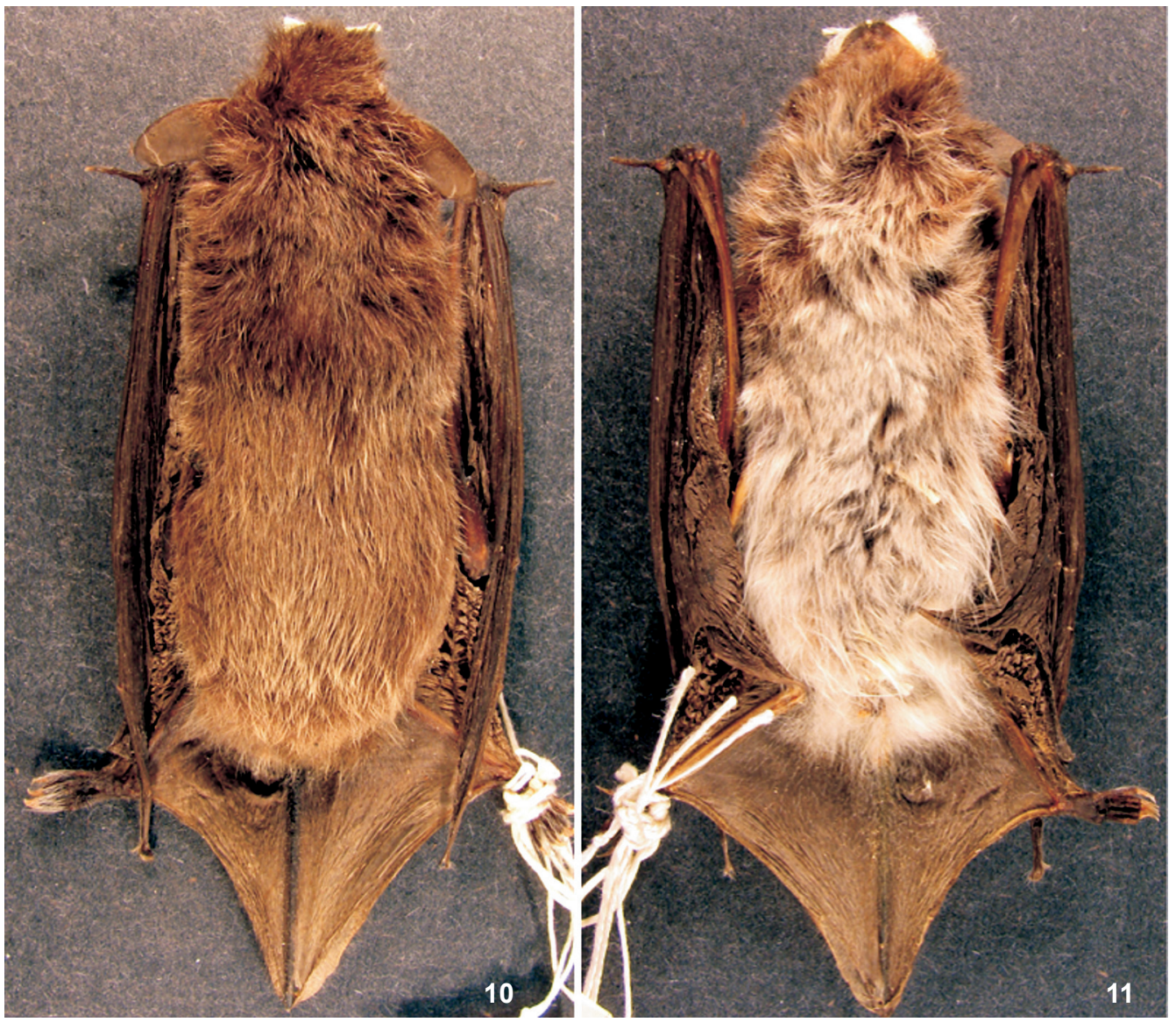

Figures 10-11. Dorsal (10) and ventral (11) views of the skin of the neotype of Myotis albescens (AMNH 205195). Forearm length 34.5 $\mathrm{mm}$. The electronic version of this article includes this figure in color.

Table IV. Vector correlation coefficients ("loadings") between original variables and principal components (PC1 and PC2) and between original variables and canonical variates (CV1 and CV2) for South American samples of Myotis albescens. Numbers in bold indicate vector correlations with magnitudes larger than $|0.29|$.

\begin{tabular}{lccccc}
\hline \multirow{2}{*}{ Characters } & \multicolumn{2}{c}{ PCA loadings } & & \multicolumn{2}{c}{ CVA loadings } \\
\cline { 2 - 3 } \cline { 5 - 6 } & PC1 & PC2 & & CV1 & CV2 \\
\hline GLS & $\mathbf{0 . 8 6}$ & 0.15 & & -0.01 & $\mathbf{0 . 6 5}$ \\
CIL & $\mathbf{0 . 8 4}$ & 0.23 & & $\mathbf{0 . 3 8}$ & $-\mathbf{0 . 6 0}$ \\
MAB & $\mathbf{0 . 7 6}$ & -0.21 & & -0.06 & -0.03 \\
BCB & $\mathbf{0 . 7 2}$ & $-\mathbf{0 . 3 4}$ & & 0.20 & -0.07 \\
IOB & $\mathbf{0 . 6 8}$ & -0.29 & & 0.14 & 0.03 \\
POB & $\mathbf{0 . 5 8}$ & $-\mathbf{0 . 7 3}$ & & $\mathbf{0 . 4 3}$ & -0.22 \\
BAC & $\mathbf{0 . 6 0}$ & 0.16 & & 0.06 & 0.02 \\
BAM & $\mathbf{0 . 6 3}$ & 0.29 & & -0.25 & 0.22 \\
MTL & $\mathbf{0 . 7 1}$ & $\mathbf{0 . 4 7}$ & & $-\mathbf{0 . 4 0}$ & 0.14 \\
M13 & $\mathbf{0 . 7 2}$ & $\mathbf{0 . 4 8}$ & & $\mathbf{0 . 5 8}$ & 0.24 \\
MAN & $\mathbf{0 . 6 6}$ & $\mathbf{0 . 5 6}$ & & 0.18 & 0.18 \\
\hline
\end{tabular}

Redescription: The neotype is a medium-sized specimen (FA $34.5 \mathrm{~mm}$, EL $12 \mathrm{~mm}$, GLS $14.41 \mathrm{~mm}$ ), with frosted, long and silky pelage (dorsal fur $6.6 \mathrm{~mm}$, ventral fur $5.0 \mathrm{~mm}$ ). Dorsal hairs are slightly bicolored, Cinnamon-brown basally (2/3 of the hair length) and Antique-brown at the tip; ventral hairs are strongly bicolored, with Mummy-brown bases (2/3) and Cinnamon-buff tips (1/3), almost totally white from the abdomen downwards and on sides of the body. Membranes are Cinnamon-brown, plagiopatagium attached at feet by a broad band of membrane and uropatagium with a fringe of hairs along its trailing edge. The skull is of moderate size (GLS $14.41 \mathrm{~mm}$, MAB $7.52 \mathrm{~mm}$ ), with broad interorbital and postorbital constrictions, and globular braincase. Sagittal crest lacking, and occipital crests low. In lateral view, rostrum slightly sloping with regard to the braincase, and occipital region rounded, projecting beyond the limit of occipital condyles. P3 is in the toothrow, not crowded to the lingual side, smaller than P2 (50\% of the total length of P2) and visible in labial view.

Type locality: The description of M. albescens, was based on the chauve souris douzième of AzARA (1801). Azara's specimen 


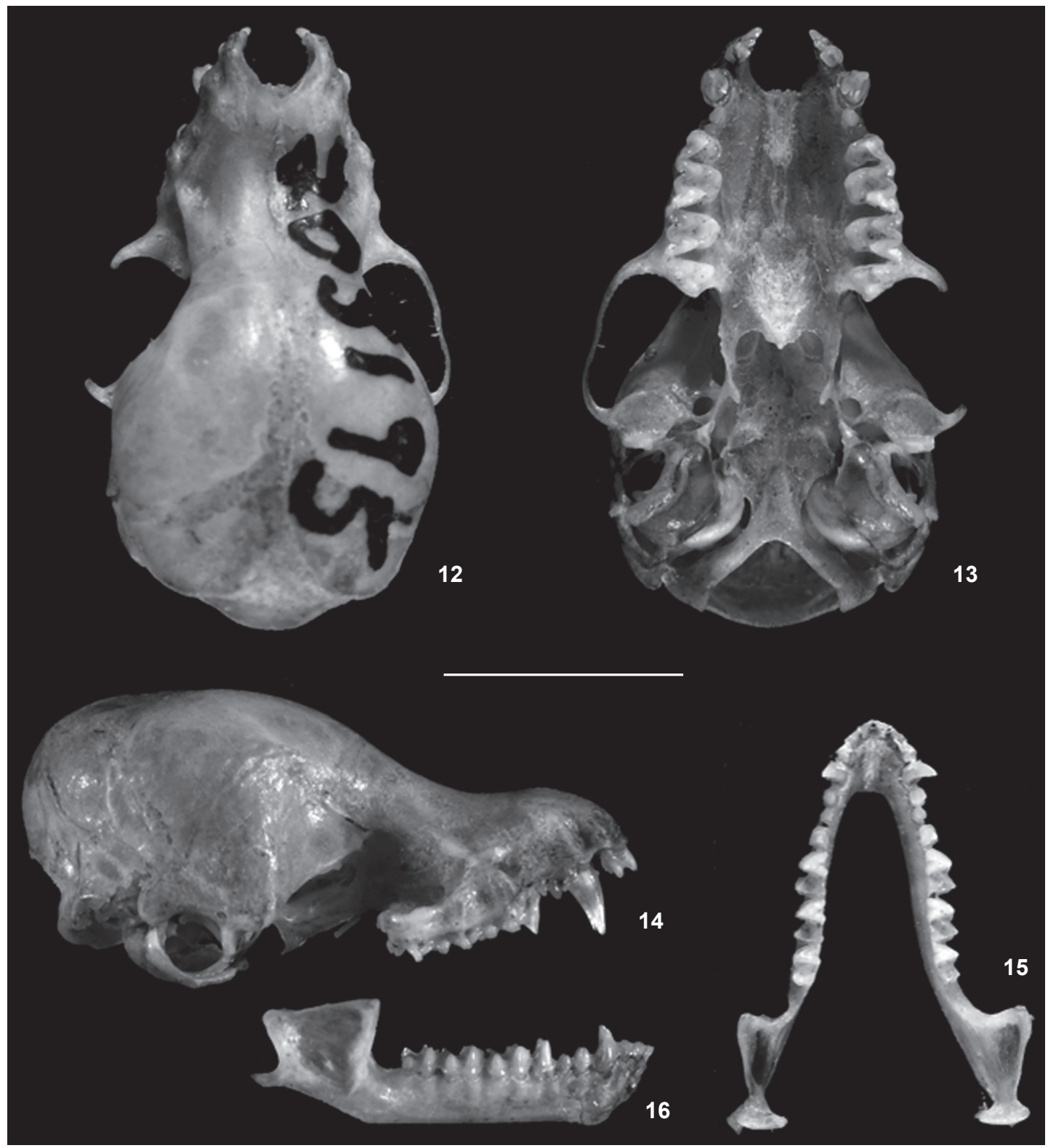

Figures 12-16. Dorsal (12), ventral (13) and lateral (14) views of the cranium and dorsal (15) and lateral (16) views of the mandible of the neotype of Myotis albescens (AMNH 205195). See text for measurements. Scale bar: $5.0 \mathrm{~mm}$.

was not preserved (WILSON 2008) and the type locality was fixed as Yaguaron, Paraguarí, Paraguay by the neotype designation of LAVAL (1973).

Remarks: As a consequence of its wide distribution across South America, M. albescens occurs in sympatry with almost all South American congeners. It differs from most of them by the presence of a fringe of hairs along the trailing edge of the uropatagium and by the frosted appearance of the dorsal pelage. The presence of a fringe of hairs on the uropatagium is a character shared with M. levis (I. Geoffroy, 1824) (Moratelli \& WiLson 2011b), and some specimens of this latter species display frosted appearance in the dorsal pelage (López-GonzÁLEz et al. 2001, Wilson 2008). When this combination occurs, $M$. albescens can be distinguished from $M$. levis by its globular braincase and smaller ear length (9-14 mm in M. albescens, and 14-18 $\mathrm{mm}$ in M. levis). Skulls of fluid preserved specimens, with a flattened braincase resembling $M$. levis, can be identified as $M$. albescens based on overall size. Regarding other species, $M$. 
albescens differs from M. atacamensis (Lataste, 1891) in having bicolored dorsal fur and the dorsal surface of the uropatagium almost naked, whereas in the last the fur extends distally on the dorsal surface of the uropatagium to a level halfway between the knee and ankle, and the dorsal fur is soft and tricolored, with black bases (LAVAL 1973); from M. aelleni Baud, 1979, M. albescens differs by the slightly bicolored fur (as opposed to tricolored); from M. chiloensis (Waterhouse, 1840) by the smaller overall size and globular braincase; from $M$. diminutus Moratelli \& Wilson, 2011 by its wider skull, globular braincase and larger overall size; from M. oxyotus (Peters, 1867) by the lighter dorsal fur coloration and smaller overall size; from M. nesopolus Miller, 1900 by the paler dorsal pelage and larger overall size; from $M$. nigricans (Schinz, 1821), M. lavali Moratelli et al., 2011, and $M$. izecksohni Moratelli et al., 2011 by its globular braincase; from M. riparius Handley, 1960, M. keaysi J.A. Allen, 1914, and M. ruber (É. Geoffroy, 1806) by the color of fur, absence of sagittal crest, globular braincase and shorter rostrum; from M. simus Thomas, 1901 by the plagiopatagium attached at toes by a broad band of membrane and silkier and longer dorsal fur (> $5 \mathrm{~mm}$ ).

\section{DISCUSSION}

Despite the number of specimens in museum collections (LAVAL 1973), the morphometric variation in M. albescens has been underestimated in previous studies. In addition, previous hypotheses of clinal variation in body size were confirmed here. Comparing specimens from Amazon basin with specimens from Mato Grosso (Brazil), Paraguay and Uruguay, LAVAL (1973) reported a possible pattern of clinal variation for two measurements with an increase in size towards the south, except for Peruvian and Ecuadorian samples. Myers \& WeTzel (1983) reported significant geographical differences in external and cranial measurements for samples from Bolivia, Chaco Boreal and eastern Paraguay, with Bolivian specimens as the most distinct. Our PCA and CVA analyzes refuted the distinctness of Peruvian and Bolivian samples regarding size and form of skull. PCA and univariate analyses revealed a southward trend of clinal variation for skull measurements, with specimens from northern South America cranially smaller than southern specimens. Results of CVA showed that the Uruguayan specimens have more elongated skulls in comparison with northern specimens. Despite the absence of central and northeastern Brazilian samples, our data revealed a southward trend of size increase. Part of the variation in M. albescens complies with Bergmann's rule, in that populations living in colder climates are larger than populations living in warmer climate regions (RENSCH 1938, MaYR 1942, 1956). This pattern is a valid ecological generalization for mammals, and has been verified for other New World species of Myotis, as well as other New and Old World species of bats (MeIre 2003). In addition to this geographic component affecting cranial size, individual variation seems to have an important role in pelage color, as previously proposed by LAVAL (1973), as well as in the size and shape of skull.

\section{ACKNOWLEDGEMENTS}

The following curators and collection staff provided access to specimens under their care: Adriano L. Peracchi (Universidade Federal Rural do Rio de Janeiro, Brazil), Leandro de O. Salles, Luiz F.B. de Oliveira, Stella M. Franco (Museu Nacional, Brazil), Fernando de C. Passos (Universidade Federal do Paraná, Brazil), Teresa Cristina C. Margarido (Museu de História Natural Capão da Imbuia, Brazil), Mario de Vivo, Juliana Barros (Museu de Zoologia da Universidade de São Paulo, Brazil), Eliana Morielle-Versute (Universidade Estadual Paulista "Julio de Mesquita Filho", Brazil), Nancy Simmons, Eileen Westwig (American Museum of Natural History, USA), Don Wilson, Linda Gordon (National Museum of Natural History, USA), Alfred Gardner (USGS Patuxent Wildlife Research Center, USA), and Patrick Boussès (Muséum National d'Histoire Naturelle, France). Nancy Simmons (American Museum of Natural History, USA) permitted the use of the images. We are grateful to Don Wilson (National Museum of Natural History, USA) for helpful reviewing the final version of the manuscript. RM was partially supported by Coordenação de Aperfeiçoamento de Pessoal de Nível Superior (CAPES, Ministério da Educação, Brazil), National Museum of Natural History (Short-Term Visitor Program Grant) and American Museum of Natural History (Collection Study Grant). This work was also supported by research fellowship to JAO (CNPq 306801/2007-8).

\section{LITERATURE CITED}

AZARA, F.D'. 1801. Essais sur l'histoire naturelle des quadrupedes de la province du Paraguay. Traduits sur le manuscrit inédit de l'auteur, par M. L. E. Moreau-Saint-Méry. Paris, Charles Pougens, 1, LXXX+366p.

Barquez, R.M.; M.A. Mares \& J.K. Braun. 1999. The bats of Argentina. Lubbock, Texas Tech University Museum, The Oklahoma Museum of Natural History, Special Publication, vol. 42, 275p.

Baud, F.J. \& H. Menu. 1993. Paraguayan bats of the genus Myotis, with a redefinition of Myotis simus (Thomas, 1901). Revue Suisse de Zoologie 100: 595-607.

Braun, J.K.; Q.D. Layman \& M.A. Mares. 2009. Myotis albescens (Chiroptera: Vespertilionidae). Mammalian Species 846: 19.

Gardner, A.L. 2008. Mammals of South America. Chicago, University of Chicago Press, vol. 1, XX+669p.

Handley Jr, C.O. 1960. Descriptions of new bats from Panama. Proceedings of the United States National Museum 112: 459-479.

HARDY, A. 1994. An examination of procedures for determining the number of clusters in a data set, p. 178-185. In: E. DIDAY; Y. Lechevallier; M. Schader; P. Bertrand \& B. Burtschy (Eds). New approaches in classification and data analysis. New York, Springer-Verlag, 693p. 
Krzanowski, W.J. \& Y.T. Lai. 1988. A criterion for determining the number of groups in a data set using sum-of-squares clustering. Biometrics 44: 23-34.

LAVAL, R.K. 1973. A revision of the neotropical bats of the genus Myotis. Natural History Museum, Los Angeles County, Science Bulletin 15: 1-54.

Little, R.J.A. \& D.B. Rubin. 1987. Statistical analysis with missing data. New York, John Wiley \& Sons, XVIII+392 p.

López-GonzÁlez, C. 2005. Murciélagos de Paraguay. Biosfera 9: 1-316.

López-González, C.; S.J. Presley; R.D. Owen \& M.R. Willig. 2001. Taxonomic status of Myotis (Chiroptera: Vespertilionidae) in Paraguay. Journal of Mammalogy 82: 138-160.

MANLY, B.F. 1994. Multivariate statistical methods, a primer. London, Chapman \& Hall, 215p.

MAYr, E. 1942. Systematics and the origin of species. New York, Columbia University Press, 334p.

MAYR, E. 1956. Geographical character gradients and climatic adaptation. Evolution 10: 105-108.

MeIre, S. 2003. On the validity of Bergmann's rule. Journal of Biogeography 30: 331-351.

Miller, G.S. \& G.M. Allen. 1928. The American bats of the genera Myotis and Pizonyx. Bulletin of the United States National Museum 144: 1-128.

Moratelli, R. \& D.E. Wilson. 2011a. A new species of Myotis (Chiroptera, Vespertilionidae) from Ecuador. Mammalian Biology 76: 608-614.

MoratelLI, R. \& D.E. Wilson. 2011b. The identity of Myotis punensis (Chiroptera: Vespertilionidae). Zoologia 28: 115-121.

Moratelli, R.; A.L. Peracchi; D. Dias \& J.A. Oliveira. 2011 a. Geographic variation in South American populations of Myotis nigricans (Schinz, 1821) (Chiroptera, Vespertilionidae), with the description of two new species. Mammalian Biology 76: 592-607.

Moratelli, R.; A.L. Peracchi \& J.A. Oliveira. 2011b. Morphometric and morphological variation in Myotis simus Thomas
(Chiroptera, Vespertilionidae), with an appraisal of the taxonomic status of Myotis guaycuru Proença based on the analysis of the type material. Zootaxa 2985: 41-54.

Myers, P. \& R.L. Wetzel. 1983. Systematics and zoogeography of the bats of the Chaco Boreal. Miscellaneous Publications of the Museum of Zoology, University of Michigan 165: $1-59$.

Neff, N.A. \& L.F. Marcus. 1980. A survey of multivariate methods for systematic. New York, Private published, $\mathrm{X}+230 \mathrm{p}$.

Rensch, B. 1938. Some problems of geographical variation and species formation. Proceedings of the Linnean Society of London, 150: 275-285.

RIDGWAY, R. 1912. Color standards and color nomenclature. Washington, D.C., Privately published, 48p.

Simmons, N.B. 2005. Order Chiroptera, p. 312-529. In: D.E. WILSON \& D.M. Reeder (Eds). Mammal Species of the World: a taxonomic and geographic reference. Baltmore, The Johns Hopkins University Press, $3^{\text {rd }}$ ed., 2142p.

Strauss, R.E. 2010. Discriminating groups of organisms, p. 7391. In: A.M.T. Elewa (Ed.). Morphometrics for nonmorphometricians. Berlin Heidelberg, Springer-Verlag, Lecture Notes in Earth Sciences 124, 367p.

Strauss, R.E.; M.N. Atanassov \& J.A Oliveira. 2003. Evaluation of the principal-component and expectation-maximization methods for estimating missing data in morphometric studies. Journal of Vertebrate Paleontology 23: 284-296.

Tномаs, O. 1901. New Myotis, Artibeus, Sylvilagus and Metachirus from South America. The Annals and Magazine of Natural History Series 7 (7): 189-193.

Thomas, O. 1902. On Azara's “Chauve-souris onzieme” (Myotis ruber, Geoff.) and a new species allied to it. The Annals and Magazine of Natural History Series 7 (10): 494-495.

Wilson, D.E. 2008. Genus Myotis Kaup 1829, p. 468-481. In: A.L. Gardner (Ed.). Mammals of South America. Chicago, University of Chicago Press, XIX+669p.

Appendix. Specimens examined. Abbreviations of institutions are as follows: Museu Nacional, Rio de Janeiro, Brazil (MN); Universidade Federal Rural do Rio de Janeiro, Seropédica, Brazil (ALP); Museu de Zoologia, São Paulo, Brazil (MZUSP); Universidade do Estado de São Paulo, São José do Rio Preto, Brazil (DZSJRP); Museu de História Natural Capão da Imbuia, Curitiba, Brazil (MHNCI); Universidade Federal do Paraná, Curitiba, Brazil (CCMZ-DZUP); American Museum of Natural History, New York, USA (AMNH); National Museum of Natural History, Washington, D.C., USA (USNM); and Museum National d'Histoire Naturelle, Paris, France (MNHN). The abbreviation JAO corresponds to field numbers of João Alves de Oliveira, and those specimens will be deposited in the mammal collection at Museu Nacional. The coordinates were obtained from the skin tags, from the Gazetteer of Marginal Localities of GARDNER (2008) and from the Google Earth Program. Individuals marked with an asterisk were used in the morphometric analyses.

Myotis albescens: BoliviA, Beni: Mamore - AMNH 209765*, 209767, 209768*, 209769, 209770, 210964, 210965*, 210966*, 210967*, 210969, 210970*, 210971, 210972*, 210973, 210975, 210976, 210977, 210978, 210979*. Beni: Marban - AMNH 210963*. Beni: Vaca Diez - 209768*. Beni: Yacuma - AMNH 210980, 210981*, 210982, 210983, 210984*, 210985*, 210986, 210987, 210988, 210989. Cochabamba: Chapare - AMNH 268648. Santa Cruz, Andres Ibanez - AMNH 264081. Santa Cruz: Sara - AMNH 246414. Rosario: unknown locality - USNM 238686. BRAZIL, Amazonas: Airão - AMNH 79530, 79531, 79702*, 79703*, 79704, 79705, 79706, 79707, 79708, 79709, 79710, 79711, 79712, 79713, 79714*, 79715, 79716, 79717, 79718, 79719, 79720*. Amazonas: Borba AMNH 91905*, 91906*, 91909*, 91910*, 92229*. Amazonas: Humaitá - DZSJRP 14113*, 14114, 14119, 14780. Amazonas: Manicoré 
- AMNH 92665*, 92666*, 92667*,92668*, 92670*,92675*,92677*, 92678*, 92679*, 92680*, 92681*. Amazonas: São Gabriel da

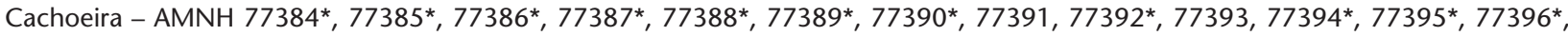
77397*, 77398*, 77399*, 77400*, 77401*, 77402*, 77403, 77404*, 77405*, 78751*, 78752*, 78753*, 78754, 78755*, 78756*, 78757*, 78758, 78759*, 78760*, 78761*, 78762, 78763*, 78764*, 78765, 78766, 78767, 78768, 78769, 78770, 78771, 78772, 78773, 78774, 78775, 78776, 78777, 78778, 78779, 78780. Pará: Altamira - MZUSP 22690*, 22692*, 22705*, 22708*, 22738*, USNM 549511, 549512, 549513, 549514, 549515, 549516. Pará: Aveiro - AMNH 94448*, 94449, 94450, 94451*, 94454*, 94455*, 94456, 94457, 94458. Pará: Baião - AMNH 97087*, 97088*, 97089*, 97090*, 97091*, 97092*, 97093*, 97094*, 97095, 97096*, 97097*, 97098*, 97099*, 97123*, 97124, 97125, 97126*, 97127*, 97273, 97274*. Pará: Belém - USNM 361774, 361775, 361776*, $361777^{*}, 361778,361779,393764 *, 460137 *, 460138$. Pará: Faro-AMNH 93926*, 93927*, 93928, 93929*, 93930, 93931*, 93932*, 93933*, 93934*, 93935*, 93936*, 93937*, 93938*. Pará: Porto de Móz - AMNH 96102*, 96103, 96104, 96105, 96106, 96107, 96108, 96109, 96110, 96111, 96112, 96113,96114, 96115, 96116, 96117, 96118, 96119, 96120. Pará: Santarém - AMNH 94444, 94445*, 94446, 94447, 94453*. Pará: Tapajós River - AMNH 94459, 94460*, 94461, 94462, 94463, 94464, 94465, 94466*, 94467*, 94468*, 94469*, 94470, 94471*, 94472*. Paraná: Mangueirinha - MHNCI-CTX 3958. Paraná: Maringá - DZSJRP 10510*. Paraná: Paiçandu-DZSJRP 10458, 10459*, 10460*, 10524*, 10525*, 10550*, 10551*, 10552*, 10553, 10554, 10555, 10556, 10557*, 10558, $10559^{*}, 10560^{*}, 10561,10562^{*}, 10563^{*}, 10564^{*}, 10565,10566^{*}, 10567,10568^{*}, 10569^{*}, 10570^{*}, 10571^{*}, 10572,10573,10574^{*}$, $10575^{*}, 10576^{*}$. Paraná: Piraquara - MHNCI 1802. Paraná: Porto Rico - CCMZ-DZUP 226*. Paraná: Quatro Barras - MHNCI-CTX 4923. Rio de Janeiro: Piraí - ALP 4659, 5165. Rio Grande do Sul: Taim - DZSJRP 14556, 14557. Roraima: Maracá - MZUSP 26849. São Paulo: Atibaia - DZSJRP 14432. São Paulo: Avanhandava - MZUSP 1292, 22691. São Paulo: Fernando Prestes - DZSJRP 13609, 13612, 13617. São Paulo: Itatiba - DZSJRP 12590. São Paulo: near Registro - DZSJRP 12554. ColombIA, Valle del Cauca: Zabaletas - USNM 483946. Ecuador, Guayas: Isla Puna - AMNH 36263. French Guiana, unknown locality: MZUSP 7647. Paraguay, Asuncion: Asuncion MZUSP 2024. Boqueron: Parque Nacional Teniente Enciso - USNM 555671. Canindeyu: Curuguaty - AMNH 234317*, 234318*, 234319*, $234320^{*}, 234323^{*}, 234324^{*}, 234326^{*}, 234328,234329^{*}, 234330,234332^{*}, 234333^{*}, 234334,234336$. Cordillera: Tacuaral - USNM 105562*, 105563, 105564*, 105565, 105566, 105567, 105568, 105569, 105570, 105571, 105572, 105575, 105576, 105577, 105578, 105579, 105580, 105581, 105582, 105583, 105584, 105585, 105661, 105662, 105664. Paraguari: Yaguaron - AMNH 205195*. Peru, Loreto: Maynas - AMNH 73235, 73237, 73239, 73242, 74018, 74019, 74021. Loreto: unknown locality - AMNH 71643*. Madre de Dios: Paktiza - USNM 564391, 564392, 566560, 566561, 566562*, 566563. Pasco: Oxapampa - AMNH 230746, $230747,230748,230750^{*}, 230751,230752,230753^{*}, 230754,230755^{*}, 230756,230757$. Pasco: San Juan - USNM 364442, 364443, $364444,364445^{*}, 364446^{*}, 364447^{*}, 364448,364449^{*}, 364450,364451,364452^{*}, 364453,364454^{*}, 364455^{*}, 364456,364457$, $364458,364459^{*}, 364460,364461,364462,364463,364464,364465,364466,364467^{*}, 364468,364469,364470,364471$, $364472,364473,364474,364475,364476 *, 364477,364478,364479,364480$. Pasco: unknown locality - AMNH $213428^{*}, 213430$. Uruguay, Artigas: Belén - AMNH 205454, 205456, 205458*, 205459, 205460*, 205462*, 205463*, 205465*, 205466*, 205468*, 205469*, 205470*, 205473*, 205474*, 205475*. VenezUela, Amazonas: Belen - USNM 405790, 405792*, 405794, 405796. Amazonas: Capibara - USNM 409392, 409395*, 416579. Amazonas: Cerro Neblina - USNM 560807*, 560808. Amazonas: Porto Ayachuco USNM 409416, 409420, 409422, 409425. Amazonas: Rio Mavaca - USNM 405798. Amazonas: San Juan - USNM 409403*, 409404, 409406, 409407, 409408*, 409410*, 409411*, 409412, 409413, 409414, 409415, 409454, 416580, 416581, 416582. Apure: Nulita - USNM 441714, 441715, 441716. Apure: Porto Paez - USNM 373909, 373913*, 373914, 373915, 373916, 373917, 374008. Bolivar: Rio Supamo - USNM 387693*. Miranda: Porto Tuy - USNM 387697, 387698, 387699, 87700*, 387701, 387702, 387703. Trujillo: Valera - USNM 370933*. Zulia: El Rosario - USNM 441718.

Myotis chiloensis: CHILE, Coastal Town N of Valparaíso: Zapallar - USNM 391785.

Myotis keaysi keaysi: BoliviA, Santa Cruz: Vallegrande - AMNH 260880, 262647. Peru, Cuzco: Cordillera Vilcabamba - AMNH 214371, 233850, 233851, 233853, 233854, 233857, 236134. Huánuco: Huánuco: AMNH 216117. Puno: Inca Mines - AMNH 15814. VeNEZUELA, Aragua: 13 km NW of Maracay (Rancho Grande Biological Station) - USNM 370901. Bolívar: Gran Sabana - AMNH 130625, 130626.

Myotis keaysi pilosatibialis: VenezuelA, Aragua: 13 km NW of Maracay (Rancho Grande Biological Station) - USNM 370929, 562920, 562921. Carabobo: Montalbán - USNM 441741, 441742. Miranda: Curupao - USNM 387714, 387715, $387716,387718$.

Myotis levis dinellii: ArGentinA, Córdoba: USNM 142560, 142561, 142562. Tucumán: La Rocha - AMNH 256987. BoliviA, Cochabamba: AMNH 261119. Chuquisaca: Tomina - AMNH 263629. Santa Cruz: Caballero - AMNH 260253. Potosí - AMNH 39003.

Myotis levis levis: ArGentinA, Buenos Aires: La Valle - USNM 236236, 236237. Córdoba - USNM 252766. Tucumán: Los Vásquez - MZUSP 2055. Entre Ríos: Puerto Constanza - USNM 582461. BraZIL, Minas Gerais: Mariana - MZUSP 1748. Minas Gerais: Ouro Preto MZUSP 15344, 15345. Paraná: Palmas - CCMZ-DZUP 380. Paraná: Porto Rico - CCMZ-DZUP 216, 217, 218, 369, 371, 372, 373, $376,377,381,382,384,385,386,387,388,389,391,392,393,394,395,396$. Rio de Janeiro: Nova Friburgo - MZUSP 2799. Rio de Janeiro: Teresópolis - ALP 6481, 6523. Rio Grande do Sul: Camapuã - AMNH 235863, 235864, 235865, 235866, 235867, 235868, $235869,235870,235871,235872,235873,235874,235875,235876,235877,235878,235879,235880,235881$. Rio Grande do

ZOOLOGIA 28 (6): 789-802, December, 2011 
Sul: Harmonia - AMNH 235892. Rio Grande do Sul: São Leopoldo - DZSJRP 10393. Rio Grande do Sul: Taim - DZSJRP 14548, 14549, 14550, 14552, 14553, 14554, 14555. Santa Catarina: Passos Maia - CCMZ-DZUP 333, 334, 335, 336. São Paulo: Boracéia - MZUSP 15224, 15225, 15273, 15274, 15304, 15305, 15306, 15307, 15308, 15309, 15358, 27491. São Paulo: Cacequí - MZUSP 3167. São Paulo: Cananéia - MZUSP 27680, 27976. São Paulo: Casa Grande - MZUSP 16473, 16474, 16475, 16476, 16477, 16478, 16479, 16480, 16481, 16482, 16483, 16484, 16485, 16486, 16487, 16488, 16489, 16490, 16491, 16492, 16493, 16494, 16495, 16496, 16497, 16498, 16499, 16500, 16501, 16502, 16503, 16504, 16505, 16506, 16507, 16508, 16509, 16510, 16477. São Paulo: Itapeva - DZSJRP 11364, 11365. Unknown locality - MNHN type 203. URUGUAY, Lavalleja: Piraraja - AMNH 205477, 205478, 205503, 205504, 205505, 205508, 205509, 205510, 205511, 205512, 205513, 205514, 205515. Tacuarembó: Yaguari - MZUSP 28979, 28981. Colón - USNM 252599. Unknown locality - MZUSP 10084, USNM 102588, 102589, 102590.

Myotis nesopolus: Venezuela, Lara: Rio Tucuyo - USNM 441710. Falcón: Capatárida - USNM 441711, 441728, 441735, 441736, 441737, 441740. Zulia: Cojoro - USNM 441721.

Myotis nigricans nigricans: BolIVIA, Cochabamba: Chapare - AMNH 211214, 211215, 211216, 211217, 211218, 211219, 211220, 211221, 211222, 211223, 211226, 211227, 211228, 211229, 211243, 211244, 211245, 211246. Santa Cruz: El Refugio - USNM 584500, 584501. BrazIL, Amazonas - MZUSP 6091. Mato Grosso do Sul: Rio Brilhante - DZSJRP 12220. Mato Grosso do Sul: Pantanal - CCMZDZUP 170, 172, 174, 176, 177. Minas Gerais: Caxambu - ALP 2182. Minas Gerais: Pains - USNM 391131. Minas Gerais: Sete Lagoas - USNM 391129. Minas Gerais: Viçosa - USNM 391132, 391133, 391135. Paraná: Balsa Nova - CCMZ-DZUP 196, 197, 198, 199, 200, 410, 419, 420, 421, 422. Paraná: Matinhos - CCMZ-DZUP 141, 142, 144, 148. Paraná: São José dos Pinhais - CCMZ-DZUP 428. Rio de Janeiro: Tinguá - ALP 2505, 2870, 6262, 6619, 6620, 6624, 6625, 6679, 6682. Rio de Janeiro: Itaguaí - ALP $2284,2290$. Rio de Janeiro: Piraí - ALP 4587, 4783. Rio de Janeiro: Rio de Janeiro - ALP 3047, 3048, 3049, 3050. Rio de Janeiro: Seropédica - ALP $585,588,589,625,626,627,628,629,630,631,636,639,640,655,658,904,1396,1826,2862,3427,3428,3498,3499$, $3581,3697,3703,3705,3715,3716,3718,3723,3740,3741,3742,3744,4815,4816,4817,4819,4825,4827,4839,4844$, 4906, 4930, 4931, 4938, 4939, 4940, 4943, 4944, 4947, 4949, 4950, 5012, 5017, 5020, 5032, 5033, 5034, 5036, 5037, 5040, 5043, 5044, 5045, 5068, 5074, 5075, 5089, 5090, 5092, 5094, 5095, 5097, 5098, 5102, 5103, 5105, 5130, 5131, 5132, 5134, $5171,5172,5173,5174,5175,5176,5179,5180,5181,5185,5186,5187,5188,5235,5327,5331,5332,5338,5340,5341$, $5342,5344,5346,5347,5348,5349,5350,5499,5501,5504,5510,5511,5520,5521,5523,5525,5543,5592,5593,5594$. Rio de Janeiro: Teresópolis - ALP 6479, 6524. Rio Grande do Sul: Frederico Westphalen - CCMZ-DZUP 338. Santa Catarina: Passos Maia - CCMZ-DZUP 400. São Paulo: Botucatu - ALP 2270, 2271. São Paulo: Fernando Prestes - DZSJRP 13616, 13619. São Paulo: São José do Rio Preto - DZSJRP 14979. São Paulo: São Sebastião - USNM 141395, 141396, 141398, 141400, 141401, 141403, 141405, 141406, 141408, 141409, 141411, 141412, 141413, 141414. ColombIA, Magdalena: Bonda - AMNH 14587. La Nariño: Ricuarte USNM 309020. La Nariño: Guayacana - USNM 309021, 309023. EcUADOR, Esmeraldas, AMNH 33239. Pichincha: Santo Domingo USNM 528566. Zamora-Chinchipe: Cumbaratza - USNM 513488, 513489. Zamora-Chinchipe: Los Encuentros - USNM 513490. San Javier - USNM 113343. Pambilar - USNM 113345, 113346. Paramba-113349. GuYANA, Upper Demerara-Bernice - USNM 582351, 582352. Panama, Canal Zone: Barro Colorado Island - USNM 296266, 296270, 296271, 296272, 296273. Darién: Boca de Cupe USNM 306796. Darién: Jaque - USNM 306796, 363085, 363086, 363087, 363088. Unknown locality - AMNH 18736. PARAGUAY, Paraguarí - USNM 115078, 115080. Boquerón (Parque Nacional Teniente Enciso) - USNM 555673, 555674. Paraguarí: Sapucay USNM 115073, 115089, 121477. Paraguarí (Ibicuy National Park) - USNM 531197. Peru, Amazonas: Cordillera Del Condor - USNM 581966, 581967. VenezUelA, Amazonas: Boca Mavaca - USNM 405801. Amazonas: Ayacucho - USNM 409424, 409455. Apure: Nulita - USNM 441722. Bolívar: Maripa - USNM 17069. Carabobo: Urama - USNM 373921, 373922, 373923, 373924, 373926, 373929, 373932, 373933, 373935, 373936, 373942, 373943, 373946, 373948, 373950. Monagas: San Agustín - USNM 409391, 409429, 409430, 409431, 409433, 409435, 409437, 409438. Yaracuy: Urama - USNM 387708.

Myotis oxyotus: Colombia, Nariño: El Guabo - USNM 309019. ECUADor, Chimborazo: Pallatanga - USNM 513480. Pastaza: Mera - USNM 548337, 548339. Pastaza: Mirador - USNM 513491, 513492, 513493, 513494. Peru, Junín: Río Palca - USNM 507204. Cuzco: Iquente - USNM 195196. Cuzco: Santa Ana - USNM 194452, 194453, 195141, 195147, 195149. Venezuela, Amazonas: Cerro Neblina - USNM 560809, 560810, 560811. 85 Km SSE Bolívar: El Dorado - USNM 387712. Mérida: Tabay - USNM 373919.

Myotis riparius: BRAzIL, Mato Grosso: Cachoeira São Simão - MN 3757. Mato Grosso do Sul: Paranaíba - DZSJRP 12022. Pará: Altamira USNM 549517, 549518. Pará: Belém - USNM 361786, 361788, 361789, 361790, 361791, 460139. Pará: Mocambo - ALP 1915, 2002, 2003, 2004, 2554, 2557, 2562, 2568, 2587, 2610, 2710. Rio de Janeiro: Tinguá - ALP 4356, 4357, 5421, 6622, $6680,6681$. Rio de Janeiro: Piraí - ALP 4573. São Paulo: Buri - MZUSP 32968, 32969, 32970. São Paulo: Juquitiba - MZUSP 32963, $32964,32966$. São Paulo: São Paulo - MZUSP 31466.

Myotis ruber: BrazIL, Minas Gerais: Viçosa - USNM 391138, 391139, 391140. Rio de Janeiro: Tinguá - ALP 6621, 6623, 6683. Rio de Janeiro: Macaé de Cima - JAO 1751, 1756, 1773. Rio de Janeiro: Teresópolis - ALP 6452, 6457, 6458, 6497, 6499, 6506, 6512, MN 3400. Rio Grande do Sul: São Lourenço do Sul - MZUSP 1298, 1988. São Paulo: Boracéia - MZUSP 28359, 28367, 28368. São Paulo: 
Buri - MZUSP 32971, 32972, 32973, 32975. São Paulo: Cananéia - MZUSP 27595. São Paulo: São Paulo - MZUSP 15254, 31470, 31471, 31472, 31473, 31971. Unknown locality - DZSJRP 17014.

Myotis simus: Bolivia, Beni: Cercado - AMNH 211155, 211156, 211167, 211168, 211169, 211170, 211171, 211172, 211173, 211174, 211178, 211179, 211180, 211181, 211182, 211183, 211190, 211192, 211193, 211194, 211195, 211196, $211197,211198$. Santa Cruz: El Refugio - USNM 584502. BrazIL, Amazonas: Borba - AMNH 91886, 91887, 91888, 91889, 91890, 91891, 91892, 94224, 94225, 94227, 94230, 94231, 94232, 94233, 94234. Amazonas: Itacoatiara - MZUSP 3472. Amazonas: Manaus - AMNH 79534, 91472, 91473, 91474, 91475, 91476, 91477, 91478, 91500. Amazonas: Parintins - 92983, 93489, 93490, 93491, 93492, 93493, 93494, 93495, 93496, 93497, 93922, 93923, 93924, 93925. Amazonas: Rio Juruá - MZUSP 638, 1074. Mato Grosso: Taiamã - MZUSP 13815. PERU, Loreto: Maynas - AMNH 71483, 71485, 71486, 71487, 71488, 71490, 71491, 71492, 71493, 71494, 74105, 74109, 74110, 74378, 74379, 74380, 74381. Loreto: Ucayali-AMNH 76240, 76241, 76242, 76243, 76244, 76245, 76246, 76247, 76248, 76249, 76252, 76253. Pasco: San Juan - USNM 364481, 364482.

Submitted: 18.V.2011; Accepted: 15.IX.2011.

Editorial responsibility: Ana Lúcia Prudente 